JSIP: Jurnal Studi Ilmu Pemerintahan

Volume 3, No 1 Februari 2022

ISSN: 2722-7405

\title{
KEMAMPUAN PENGGUNAAN TEKNOLOGI DAN MANAJEMEN RISET DALAM UPAYA MENGURANGI RISIKO BENCANA DI KABUPATEN BIMA
}

\author{
Suraya ${ }^{1}$, Haeril ${ }^{2}$ \\ 1,2, Program Studi Ilmu Pemerintahan, Sekolah Tinggi Ilmu Sosial dan Ilmu Politik (STISIP) Mbojo Bima, \\ Indonesia \\ Email:amrin5172@gmail.com
}

\begin{abstract}
Article Info
Keyword:

Technology ${ }^{1}$,

Research ${ }^{2}$,

Disaster Risk

Management ${ }^{3}$.

Abstract: Local governments have problems in anticipating disasters, especially in the support of technology and communication system facilities. As a result, many casualties occurred repeatedly every time a natural disaster occurred. The urgency of the research is to describe the ability to use information technology and sustainable management research as an effort to reduce disaster risk in Bima Regency. The results of the study indicate that the operation of the Operations Control Center has provided improved performance in disaster management by the Regional Disaster Management Agency (BPBD) of Bima Regency. With the availability of a set of communication tools in the form of a mondopad monitor and radio communication for coordination in disaster management in the region to BNPB. The results of the research were then disseminated and disseminated, as well as disaster response simulations on campuses and schools in Bima Regency by involving international NGOs. In addition, the publication of research results can be used as a guide to reduce vulnerability by carrying out structural and non-structural mitigation. Basic efforts that can be done by empowering the results of applied research from universities and research related to disaster management. One of them is through the study of the ratio of investment to each phase of disaster management.
\end{abstract}

Kata Kunci:

Teknologi ${ }^{1}$,

Penelitian',

Manajemen Risiko

Bencana $^{3}$.

\begin{abstract}
Abstrak: Pemerintah daerah memiliki masalah dalam upaya mengantisipasi bencana khususnya dalam dukungan sarana sistem teknologi dan komunikasi. Akibatnya terjadi jatuhnya korban jiwa dalam jumlah besar korban berulang kali setiap kali bencana alam datang. Urgensi dari penelitian adalah untuk mendeskripsikan kemampuan penggunaan teknologi informasi dan riset manajemen yang berkelanjutan sebagai upaya pengurangan risiko bencana di Kabupaten Bima. Hasil penelitian menunjukkan bahwa dengan pengoperasian Pusat Pengendalian Operasi telah memberikan peningkatan kinerja dalam penanganan bencana oleh Badan Penanggulangan Bencana Daerah (BPBD) Kabupaten Bima. Dengan ketersediaan seperangkat alat komunikasi berupa monitor mondopad dan komunikasi radio untuk koordinasi dalam penanganan bencana di daerah ke BNPB. Hasil penelitian tersebut kemudian disosialisasikan dan diseminasi, serta simulasi tanggap bencana di kampus maupun sekolah-sekolah bi Kabupaten Bima dengan melibatkan LSM internasional. Selain itu publikasi hasil riset dapat dijadikan panduan untuk mengurangi kerentanan dengan melakukan mitigasi struktural maupun non struktural. Upaya dasar yang dapat dilakukan dengan pemberdayaan hasil riset terapan baik dari perguruan tinggi maupun penelitian yang berkaitan penanggulangan bencana. Salah satunya melalui kajian rasio perbandingan investasi terhadap setiap fase penanggulangan bencana.

Article History: Received 2-Desember-2021, Revised 9-Januari-2022, Accepted: 13-Februari-2022
\end{abstract}

\section{PENGANTAR}

Pada dasarnya wilayah Kabupaten Bima sebagian besar (70\%) merupakan daerah pegunungan bertekstur dataran tinggi sehingga rawan longsor dan banjir bandang setiap tahunnya (Sopiawati, 2019). Menurut data Kompas dan republika tahun 2021, dari bulan januari 
sampai maret 2021, sebagian besar wilayah Kabupaten Bima diterjang banjir parah di Kecamatan Sanggar, Monta, Wera, Bolo, Palibelo, dan Sape.

Selain itu, bencana di Kabupaten Bima juga dominasi oleh gempa bumi, gelombang pasang, banjir rob dan abrasi, kebakaran hutan, kekeringan, cuaca ekstrem, gunung api, keracunan akibat intrusi air laut, epidemi, dan wabah penyakit (Faizah \& Buchori, 2018).

Dari data ditas maka penyelenggaraan penanggulangan bencana beserta tindakan-tindakan antisipasinya merupakan syarat mutlak untuk dapat hidup berdampingan dengan bencana alam. Perlu political will Pemerintah untuk dapat memprioritaskan program manajemen bencana secara terintegrasi yang meliputi prabencana, saat tanggap darurat, dan pasca bencana, serta kegiatan sosialisasinya kepada masyarakat (Handayani, 2011).

Namun, penanggulangan bencana selama ini hanya bertumpu pada masalah saat bencana dan beberapa penyebabnya. Sedangkan kegiatan antisipasi dan upaya memperkirakan konsekuensi potensial bahaya tertentu belum maksimal dilakukan, kelembagaan yang tidak fleksibel dan kurang sigap, struktur sistem peringatan dini dan sosialisasi yang tidak efektif bagi seluruh lapisan masyarakat menjadi kendala dalam upaya penyelenggaraan penanggulangan bencana (Faturahman, 2017).

Untuk itu agar tidak menimbulkan dampak negatif terhadap kerugian ekonomi, sosial, psikologis, dan ekologis yang lebih besar, maka paradigma penanggulangan bencana harus bersifat preventif dan dilakukan dengan komitmen secara kelembagaan (Ulum, 2014). Selain itu juga diperlukan terobosan kebijakan yang efektif dan inovasi, penanggulangan bencana juga merupakan aktivitas yang sangat kompleks, multi stakeholder, multi-dimensional, dan multi disiplin ilmu, sehingga penanganannya memerlukan tekonologi tepat guna dan kolaborasi secara kelembagaan (Djalante, 2012).

Sebab selama ini Pemerintah Daerah tampaknya memiliki kegagapan dalam upaya mengantisipasi bencana khususnya dalam dukungan sarana sistem tekonlogi dan komunikasi dalam penanggulangan bencana. Dukungan sistem tekonologi dan komunikasi yang tidak memadai akan berdampak pada macetnya koordinasi dan penanganan cepat. Akibat yang lebih parah lagi adalah terjadinya kegagapan dan jatuhnya korban jiwa dalam jumlah besar yang senantiasa terulang kembali tiap kali bencana alam datang.

Untuk itu menjadi penting untuk pemanfaatan teknologi, pengetahuan, informasi, dan sumber daya manusia dalam penanggulangan bencana sebagai upaya pengurangan risiko bencana di Kabupaten Bima.

\section{METODE PENELITIAN}

Penelitian ini menggunakan metode deskriptif kualitatif. Lokasi penelitian ini berada di Badan Penanggulangan Bencana Daerah (BPBD) Kabupaten Bima, lokasi tersebut sangat strategis dalam melihat studi kasus dan permasalahan yang terjadi. Subyek penelitian ini dipilih melalui teknik nonprobability sampling, dengan menggunakan teknik purposive sampling atau teknik penentuan sampel dengan mempertimbangkan aspek tertentu. Teknik pengumpulan data terdiri atas observasi (observation), wawancara (interview), dan dokumentasi (documentation). Setelah data selesai dikumpulkan dengan lengkap dari lapangan, tahap berikutnya yang harus lakukan adalah tahap analisa data. Dalam penelitian ini menggunakan teknik analisa data model interaktif menurut Miles dan Huberman yang terdiri dari dari tiga hal utama, yaitu; reduksi data, penyajian data, dan penarikan kesimpulan/verifikasi.

\section{HASIL DAN DISKUSI}

\section{Penggunaan Teknologi dalam Penanganan Bencana}

Menurut Sosiawan (2014), salah satu sarana yang vital diperlukan dalam penanggulangan bencana alam adalah teknologi komunikasi dan informasi. Bencana-bencana besar yang pernah terjadi di Aceh, Yogyakarta, Sumatra Barat dan Daerah-daerah yang rawan bencana, dimana pada saat terjadi bencana semua sarana komunikasi publik lumpuh total sehingga menyebabkan terjadinya berbagai isu yang tidak jelas yang menyebabkan kepanikan luar biasa bagi masyarakat.

Kabupaten Bima merupakan salah satu daerah di Indonesia yang tergolong rawan bencana. Maka dari itu akan sangat membantu jika penggunaan teknologi maju diterapkan dalam 
penanganan bencana terutuama ketika bencana alam datang agar lebih cepat mendapat respon dari pusat. Selain itu, penggunaan teknologi juga untuk mempermudah koordinasi dalam penanganan bencana di Kabupaten Bima.

Sebab respon cepat penanganan bencana merupakan salah satu indikator kinerja penanggulangan bencana di Daerah. Sebagai bentuk peningkatan kinerja penanganan bencana Badan Penanggulangan Bencana Daerah (BPBD) Kabupaten Bima sudah didukung pengoperasikan Pusat Pengendalian Operasi (Pusdolops) Penanganan Bencana.

Saat ini Badan Penaggulangan Bencana Daerah (BPBD) Kabupaten Bima, telah mendapatkan hibah seperangkat alat komunikasi berupa 1 monitor mondopad 2.0 ukuran 80 inci. Alat ini digunakan untuk berkoordinasi dalam penangan bencana di daerah ke BNPB.

Monitor mondopad senilai Rp 1,6 miliar, merupakan alat tercepat untuk mengatasi penanganan bencana di Kabupaten Bima. Perangkat ini menggunakan prosesor Intel i 7 dan RAM sebesar $8 \mathrm{~GB}$, konektivitas Bluetooth 4.0 dan HDMI, serta pilihan-pilihan kamera dengan sambungan USB 3.0 yang bisa digunakan untuk video call ke BNPB dan kantor BPBD di seluruh Indonesia. Sehingga ketika ada bencana, Pusdalop bisa menerima laporan melalui siaran videocall dan radio langsung dari lokasi bencana. Informasi tersebut diverifikasi dan selanjutnya dikirim ke Pusat Data dan Informasi (Pusdatin) BNPB Jakarta. BPBD Bima juga mendapat bantuan 1 unit radio komunikasi dari BNPB RI, yang terhubung langsung ke BNPB dan kantor BPBD di seluruh Indonesia. Secara teknis, perangkat radio ini menjadikan komunikasi radio terkait kebencanaan hanya terpusat di BPBD. Radio amatir tidak lagi mengeluarkan statement sendirisendiri berkaitan dengan informasi kebencanaan yang bisa menimbulkan bias informasi dan kepanikan di tengah masyarakat.

Pusdalops (Pusat Pengendalian Operasi) Penanggulangan Bencana di BPBD Kabupaten Bima juga dilengkapi beberapa unit komputer untuk verifikasi dan pengolahan data kebencanaan. Kehadiran perangkat komunikasi canggih ini diharapkan semakin mempercepat akses informasi dan kaji cepat dampak bencana oleh personel BPBD. Disamping memudahkan mitigasi bencana dan semakin cepat mengambil keputusan dalam penanganan bencana. Soal jaringan informasi, BPBD Kabupaten Bima sudah melakukan kolaborasi dengan BMKG sehingga pemantauan iklim dan cuaca bisa diinformasikan langsung dari BPBD.

Selain itu pada tahun 2020, BPBD Kabupaten Bima mendapat bantuan dari BNPB dan BMKG kaitannya dengan alat pendeteksi longsor yang telah terpasang di Kecamatan Lambitu sebagai kawasan rawan longsor. Dimana alat tersebut berfungsi untuk mengidentifikasi retakan tanah. Selain itu, BPBD juga mendapatkan bantuan alat pendeteksi gempa atau alat pemantau gempa Seismograf. Alat tersebut dipergunakan untuk mendeteksi gempa bumi atau getaran pada permukaan tanah. Ketika gempa terjadi maka akan segera dideteksi, maka pena pada seism ograf akan bergerak menggambarkan tingkat getaran pada kertas.

BPBD Kabupaten Bima juga mendapat bantuan dari BNPB dan BMKG kaitannya dengan alat pendeteksi longsor yang telah terpasang dilambitu, untuk mengidentifikasi retakan tanah, kemudian BPBD juga mendapatkan bantuan alat pendeteksi gempa atau alat pemantau gempa artinya kalaupun gempa terjadi alat itu bisa dengan sekejap mengukur kekuatan gempa dan mengidentifikasi titik pusat gempa sehingga kalaupun magnitudo gempa tinggi, alat itu akan menginstruksikan langkah-langkah yang harus dilakukan oleh Kepala daerah terkait dengan Kesiapsiagaan.

Untuk melihat efektifitas dari penggunaan Teknologi Informasi dalam penanganan Kebencanaan di Kabupaten Bima, dapat dilihat pada tabel indeks ketahanan Daerah Kabupaten Bima dibawah ini. Berikut adalah tabel hasil kajian tingkat ketahanan Kabupaten Bima berdasarkan hasil survey Indiktor HFA:

Tabel 1. Indeks Ketahanan Daerah Kabupaten Bima berdasarkan Survey HFA:

\begin{tabular}{llcc}
\hline No. & \multicolumn{1}{c}{ Prioritas } & Nilai Prioritas & Indeks Prioritas \\
\hline 1. & $\begin{array}{l}\text { Memastikan bahwa pengurangan resiko bencana menjadi } \\
\text { sebuah prioritas nasional dan lokal dengan dasar } \\
\text { kelembagaan yang kuat untuk pelaksanaannya }\end{array}$ & 82,5 & 4 \\
\hline 2. & $\begin{array}{l}\text { Mengidentifikasi, mengkaji dan memantau rasio bencana } \\
\text { dan meningkatkan peringatan dini }\end{array}$ & 62,5 & 3 \\
\hline
\end{tabular}




\begin{tabular}{clcc}
\hline 3. & $\begin{array}{l}\text { Menggunakan pengetahuan, inovasi dan Pendidikan untuk } \\
\text { mebangun suatu budaya keselamatan dan ketahanan } \\
\text { disemua tingkat }\end{array}$ & 30 & 1 \\
\hline $4 . \quad$ Mengurangi factor-faktor risiko yang mendasar & 63,75 & 3 \\
\hline 5. $\begin{array}{l}\text { Memperkuat kesiapsiagaan terhadap bencana demi resfon } \\
\text { yang efektif disemua tingkat }\end{array}$ & 83,75 & 4 \\
\hline Total nilai prioritas & $\mathbf{6 4}$ & $\mathbf{3}$ \\
\hline Indeks ketahanan daerah & & \\
\hline
\end{tabular}

Sumber: Dokumen RPB Kab. Bima tahun 2018-2022

Berdasarkan data tabel di atas, maka Indeks ketahanan bencana Kabupaten Bima berada pada level 3. Hal ini menjelaskan bahwa Kabupaten Bima telah melaksanakan beberapa tindakan pengurangan risiko bencana dengan pencapaian-pencapaian yang masih bersifat sporadis yang disebabkan belum adanya komitmen kelembagaan dan/atau kebijakan sistematis serta lemahnya daya dukung anggaran dalam penanggulangan bencana. Pencapaianpencapaian kecil dalam pengurangan risiko bencana di Kabupaten Bima telah ada dengan melaksanakan beberapa tindakan maju dalam rencana-rencana atau kebijakan.

Berikut adalah penjelasan dari masing-masing indikator tersebut berdasarkan kemampuan daerah. Indeks indikator ini akan menentukan indeks prioritas, dan selanjutnya dapat ditentukan tingkat ketahanan Daerah. Tingkat ketahanan daerah berdasarkan skala indeks 5-1, dengan arti masing-masing level sebagai berikut :

a. Indeks/ Level 5, dimana capaian komprehensif telah dicapai dengan komitmen dan kapasitas yang memadai disemua tingkat komunitas dan jenjang pemerintahan.

b. Indeks/ Level 4, Dengan dukungan komitmen serta kebijakan yang menyeluruh dalam pengurangan risiko bencana disuatu daerah telah memperoleh capaian-capaian yang berhasil, namun diakui masih ada keterbatasan dalam komitmen, sumber daya finansial ataupun kapasitas operasional dalam pelaksanaan upaya pengurangan risiko bencana di daerah tersebut.

c. Indeks/ Level 3, Komitmen pemerintah dan beberapa komunitas tekait pengurangan risiko bencana di suatu daerah telah tercapai dan didukung dengan kebijakan sistematis, namun capaian yang diperoleh dengan komitmen dan kebijakan tersebut dinilai belum menyeluruh hingga masih belum cukup berarti untuk mengurangi dampak negatif dari bencana.

d. Indeks/ Level 2, Daerah telah melaksanakan beberapa tindakan pengurangan risiko bencana dengan pencapaian-pencapaian yang masih bersifat sporadis yang disebabkan belum adanya komitmen kelembagaan dan/atau kebijakan sistematis.

e. Indeks/ Level 1, Daerah telah memiliki pencapaian-pencapaian kecil dalam upaya pengurangan risiko bencana dengan melaksanakan beberapa tindakan maju dalam rencana-rencana atau kebijakan.

Dengan demikian untuk meningkatkan dari indeks/level 3 sampai pada level 5 agar tercipta daerah dengan tingkat ketahanan terbaik untuk mengurangi resiko bencana, maka perlu diupayakan tindakan-tindakan dan rencana-rencana yang sistematis yang di dukung sepenuhnya oleh lembaga Pemerintah dan seluruh masyarakat Kabupaten Bima dengan komitmen yang kuat dalam pengurangan risiko bencana.

\section{Manajemen Riset dan Pengembangan}

Demikian dalam upaya melaksanakan riset yang berkelanjutan. Pada dasarnya riset tentang kebencanaan sebagai langkah untuk mengetahui ancaman dan potensi, memperkuat protokol kebencanaan, guna meminimalisir risiko. Melalui publikasi hasil riset secara resmi, masyarakat diharapkan lebih memahami lokasi yang menjadi tempat tinggalnya, apakah berpotensi ancaman bencana tertentu atau tidak.

Riset-riset kebencanaan bermanfaat membuat Pemerintah Daerah dan masyarakat lebih waspada dan antisipatif terhadap potensi terjadinya bencana. Karena secara teknologi belum ada yang bisa memprediksi kapan bencana itu akan terjadi. Untuk itu, mitigasi terhadap dampak bencana melalui upaya riset kebencanaan perlu terus di perkuat. 
Demikian Pemerintahan daerah Kabupaten Bima perlu menerapkan hasil riset kejadian bencana secara maksimal dan terstruktur. Untuk memaksimalkan hasil risat kejadian bencana tersebut, pemerintah daerah perlu mempublikasikan hasil riset tersebut kepada pemangku kepentingan terkait penanggulangan bencana dan masyarakat di Kabupaten Bima. Kerjasama pemerintah Kabupaten Bima dengan lembaga-lembaga pendidikan yang ada di Kabupaten Bima baik tingkat dasar maupun perguruan tinggi perlu dilakukan, karena keberlanjutan pembangunan ketahanan dan budaya aman di suatu daerah secara terus menerus amat bergantung kepada pendidikan dan pengetahuan.

Pengurangan risiko bencana diajarkan di lembaga pendidikan formal tidak hanya dalam bentuk teori tetapi juga praktek terkait pengurangan risiko bencana. Salah satu indikator keberhasilan upaya pengurangan risiko daerah dapat dilihat dari rendahnya biaya pemulihan pasca bencana. Metode pengurangan biaya pemulihan dilakukan berdasarkan riset-riset yang dilaksanakan oleh para ahli dan akademisi. Riset tersebut ditujukan tidak hanya untuk memenuhi kebutuhan para ahli semata tetapi juga harus mampu diterapkan pada tingkat rumah tangga.

Dalam dokumen Rencana Penanggulangan Bencana Daerah Kabupaten Bima Tahun 20182022, mengupayakan melalui kegiatan riset kebencanaan yang berkelanjutan diharapkan adanya perubahan jangka panjang yang berfokus pada pergeseran paradigma untuk pengurangan risiko bencana yang lebih efektif. Pola pergeseran paradigma dapat menggunakan pengembangan strategi pendidikan dan penyadaran pada pendidikan formal, nonformal, informal dan maupun sosialilasi informasi lewat media Pemerintah Daerah.

Pergeseran paradigma ini diharapkan membuat trend baru dan bagian dari gaya hidup modern di masyarakat Kabupaten Bima. Sangat penting untuk membangun paradigma ini menjadi sesuatu yang dihargai dan berkembang dengan pola-pola yang mungkin ditiru oleh masyarakat. Upaya dasar yang dapat dilakukan dengan pemberdayaan hasil riset terapan baik dari perguruan tinggi maupun penelitian yang berkaitan penanggulangan bencana. Salah satunya melalui kajian rasio perbandingan investasi (cost benefit analys) terhadap setiap fase penanggulangan bencana.

Selain itu dapat dikembangkan juga hasil riset yang dapat diterapkan secara langsung oleh individu dan keluarga seperti pembangunan rumah aman Gempa, sumur resapan dan lain lain. Diharapkan dengan adanya beberapa riset terkait penanggulangan bencana di Kabupaten Bima dapat menurunkan kerentanan daerah terhadap risiko multi bahaya.

Berikut adalah tabel program dan kegiatan dalam strategi penelitian dan pendidikan, serta rencana aksinya dalam Penaggulangan Bencana di Kabupaten Bima:

Tabel 2. Rencana Aksi untuk Penelitian dan Pendidikan

\begin{tabular}{|c|c|c|c|c|c|}
\hline \multirow{2}{*}{ Aksi } & \multirow{2}{*}{ Indikator } & \multirow{2}{*}{$\begin{array}{l}\text { Keterbatasan } \\
\text { Instansi }\end{array}$} & \multicolumn{3}{|c|}{ Sumber Penganggaran } \\
\hline & & & Mandiri & Kerjasama & Vertikal \\
\hline $\begin{array}{l}\text { Pengintegrasian hasil } \\
\text { riset kedalam } \\
\text { kebijakan dan } \\
\text { perencanaan } \\
\text { penanggulangan } \\
\text { bencana }\end{array}$ & $\begin{array}{l}\text { Pengintegrasian hasil } \\
\text { riset kedalam } \\
\text { kebijakan dan } \\
\text { perencanaan } \\
\text { penanggulangan } \\
\text { bencana }\end{array}$ & $\begin{array}{l}\text { Uatama: BPBD } \\
\text { Pendukung: Perguruan } \\
\text { Tinggi, BAPPEDA, } \\
\text { DISHUBKOMINFO, } \\
\text { BMKG, BPMPKB, PU, } \\
\text { Bagian Hukum } \\
\end{array}$ & $30 \%$ & $50 \%$ & $20 \%$ \\
\hline $\begin{array}{l}\text { Penerapan hasil riset } \\
\text { dalam pemanfaatan } \\
\text { bangunan sekolah dan } \\
\text { kantor pemerintahan } \\
\text { sebagai tempat } \\
\text { pengungsian } \\
\text { sementara }\end{array}$ & $\begin{array}{l}\text { Diterapkannya hasil } \\
\text { riset dalam } \\
\text { pemanfaatan } \\
\text { bangunan sekolah dan } \\
\text { kantor pemerintahan } \\
\text { sebagai tempat } \\
\text { pengungsian } \\
\text { sementara } \\
\end{array}$ & $\begin{array}{l}\text { Uatama: BPBD } \\
\text { Pendukung: Perguruan } \\
\text { Tinggi, BAPPEDA, } \\
\text { DISHUBKOMINFO, } \\
\text { BMKG, BPMPKB, PU, } \\
\text { Bagian Hukum }\end{array}$ & $30 \%$ & $50 \%$ & $20 \%$ \\
\hline
\end{tabular}

\section{Sumber: Dokumen RPB Tahun 2018-2022}

Selain itu, Pelaksanaan kegiatan Riset BPBD bersama TIM riset UGM dimana alokasi anggarannya dari BNPB, juga bersama NGO dan LP2DM kaitan dengan riset dan penyusunan Peta Potensi Bencana dan Dokumen RPB. BPBD Aktif melukan sosialisasi dan diseminasi tentang Potensi Kebencanaan dan simulasi tanggap bencana kebakaran di Kampus dan Sekolah-sekolah yang melibatkan NGO internasional seperti Islamic Center. Hasil-hasil riset kerjasama tersebut diharapkan sebagai upaya Pencegahan bahaya yang lebih kepada pengurangan tingkat risiko yang akan muncul dengan melakukan pengelolaan pada lokasi sumber bahaya. Selain itu 
publikasi hasil riset dapat dijadikan panduan untuk pengurangan Kerentanan dengan melakukan mitigasi struktural maupun nonstruktural. Tentunya dapat meningkatkan kapasitas daerah terutama pengetahuan pemerintah maupun masyarakat dalam upaya pengurangan risiko bencana dengan mengetahui jenis ancaman dan dampak kejadian.

\section{KESIMPULAN}

Sebagai bentuk peningkatan kinerja penanganan bencana Badan Penanggulangan Bencana Daerah (BPBD) Kabupaten Bima sudah didukung pengoperasikan Pusat Pengendalian Operasi (Pusdolops) Penanganan Bencana. Dengan ketersediaan seperangkat alat komunikasi berupa monitor mondopad dan radio komunikasi. Alat ini digunakan untuk berkoordinasi dalam penangan bencana di daerah ke BNPB. Pusdalops Penanggulangan Bencana di BPBD Kabupaten Bima juga dilengkapi beberapa unit komputer untuk verifikasi dan pengolahan data kebencanaan. Ketersediaan alat pendeteksi longsor yang telah terpasang di kawasan rawan longsor. Juga alat pendeteksi gempa atau alat pemantau gempa Seismograf untuk mendeteksi gempa bumi atau getaran pada permukaan tanah. Selain itu sebagai upaya mengurangi risiko bencana yang terjadi BPBD berupaya melaksanakan riset yang berkelanjutan untuk perubahan jangka panjang yang berfokus pada pergeseran paradigma untuk pengurangan risiko bencana yang lebih efektif. Hasil riset tersebut kemudian disosialisasikan dan diseminasi, serta simulasi tanggap bencana di kampus maupun sekolah-sekolah bi Kabupaten Bima dengan melibatkan NGO internasional. Selain itu publikasi hasil riset dapat dijadikan panduan untuk pengurangan kerentanan dengan melakukan mitigasi struktural maupun nonstruktural. Upaya dasar yang dapat dilakukan dengan pemberdayaan hasil riset terapan baik dari perguruan tinggi maupun penelitian yang berkaitan penanggulangan bencana. Salah satunya melalui kajian rasio perbandingan investasi (cost benefit analys) terhadap setiap fase penanggulangan bencana.

\section{REFERENSI}

Djalante, R. (2012). Adaptive Governance and Resilience: The Role Of Multi-Stakeholder Platforms In Disaster Risk Reduction.

Dokumen RPB BPBD Kabupaten Bima Tahun 2018-2022

Faturahman, B. M. (2017). Reformasi Administrasi Dalam Manajemen Bencana. Mimbar Yustitia, $1(2), 185-201$.

Faizah, N., \& Buchori, I. (2018). Model Pemetaan Risiko Kekeringan Di Kabupaten Bima, Nusa Tenggara Barat (Doctoral Dissertation, Universitas Diponegoro).

Handayani, R. (2011). Analisis Partisipasi Masyarakat Dan Peran Pemerintah Daerah Dalam Pelaksanaan Manajemen Bencana Di Kabupaten Serang Provinsi Banten.

Idrus, Muhammad. 2009. Metode Penelitian Ilmu Sosial "Pendekatan kualitatif dan Kuantitatif" edisi kedua. Jakarta. Erlangga.

Sugiyono. (2014). Metode penelitian kuantitatif, kualitatif, dan R\&B. Alfabeta. Bandung

Sopiawati, N. (2019, June). The Role of Women In The Management Of Flood Disasters In Bima District, Nusa Tenggara Barat. In Iop Conference Series: Earth and Environmental Science (Vol. 271, No. 1, P. 012030). Iop Publishing.

Sosiawan, E.A. (2014). Model ideal manajemen tekonologi informasi dan komunikasi dalam mendukung operasional penanganan bencana alam. Jurnal ilmu Pengetahuan dan teknologi Komunikasi, 17(2), 175-188

Ulum, M. C. (2014). Manajemen Bencana: Suatu Pengantar Pendekatan Proaktif. Universitas Brawijaya Press. Malang.

Wijayanti, I., Pneumatica, O., \& Nurjannah, S. (2018). Perempuan Bima dan Strategi Adaptasi Pasca Bencana Banjir Bandang (Studi Kasus Peran Perempuan di Kabupaten Bima, NTB). Simulacra: Jurnal Sosiologi, 1(1), 5-18. 